\title{
Large aperture N31 neodymium phosphate laser glass for use in a high power laser facility
}

\author{
Lili Hu, Shubin Chen, Jingping Tang, Biao Wang, Tao Meng, Wei Chen, Lei Wen, Junjiang Hu, Shunguang \\ $\mathrm{Li}$, Yongchun $\mathrm{Xu}$, Yasi Jiang, Junzhou Zhang, and Zhonghong Jiang \\ Shanghai Institute of Optics and Fine Mechanics, Chinese Academy of Sciences, Shanghai 201800, China \\ (Received 17 October 2013; revised 13 December 2013; accepted 10 January 2014)
}

\begin{abstract}
Large aperture Nd:phosphate laser glass is a key optical element for an inertial confinement fusion (ICF) facility. N31, one type of neodymium doped phosphate glasses, was developed for high peak power laser facility applications in China. The composition and main properties of N31 glass are given, together with those of LHG-8, LG-770, and KGSS$0180 \mathrm{Nd}$ :phosphate laser glasses, from Hoya and Schott, and from Russia. The technologies of pot melting, continuous melting, and edge cladding of large size N31 phosphate laser glass are briefly described. The small signal gain profiles of N31 glass slabs from both pot melting and continuous melting at various values of the pumping energy of the xenon lamp are presented. N31 glass is characterized by a stimulated emission cross section of $3.8 \times 10^{-20} \mathrm{~cm}^{2}$ at $1053 \mathrm{~nm}$, an absorption coefficient of $0.10-0.15 \% \mathrm{~cm}^{-1}$ at laser wavelength, small residual stress around the interface between the cladding glass and the laser glass, optical homogeneity of $\sim 2 \times 10^{-6}$ in a $400 \mathrm{~mm}$ aperture, and laser damage threshold larger than $42 \mathrm{~J} / \mathrm{cm}^{2}$ for a $3 \mathrm{~ns}$ pulse width at $1064 \mathrm{~nm}$ wavelength.
\end{abstract}

Keywords: neodymium phosphate laser glass; large aperture glass; ICF facility

\section{Introduction}

Large aperture Nd:phosphate laser glass is at the heart of a high power laser system. For high peak power inertial confinement fusion (ICF) facility application, there are many strict technical requirements on laser glass, such as high gain, low nonlinear refractive index, low attenuation at laser wavelength, excellent optical homogeneity, and large laser damage threshold. Large aperture Nd:phosphate laser glasses have been successfully applied in the NIF facility in the United States, and an over 2 MJ ultraviolet laser has already been realized in this largest laser facility ${ }^{[1,2]}$. Phosphate glass has good solubility to rare earth ions, medium phonon energy, low nonlinear refractive index, strong ability to resolve platinum particles, and good spectroscopic properties for $\mathrm{Nd}^{3+}$ ions compared with silicate glass. Since the late 1970s, Nd:phosphate laser glass has been developed for high peak power laser facility use. LHG-8 and LG-770 Nd:phosphate laser glasses, which are used in the NIF facility in the United States, were developed and fabricated by Hoya and Schott, with continuous melting technology ${ }^{[3]}$. KGSS-0180 Nd:phosphate glass was developed in Russia, and it has been used in the four-channel

Correspondence to: Lili $\mathrm{Hu}$, Shanghai Institute of Optics and Fine Mechanics, Chinese Academy of Sciences, Shanghai 201800, China. Email: hulili@siom.ac.cn laser system "Luch"[4]. In China, N21 and N31, two types of $\mathrm{Nd}$ :phosphate laser glass, have been used in high power laser facilities. N21 Nd:phosphate laser glass was developed in the 1980s in Shanghai Institute of Optics and Fine Mechanics (SIOM), and it was used in Shen Guang I and Shen Guang II high peak power laser facilities ${ }^{[5,6]}$. N31 Nd:phosphate laser glass was developed in Shanghai Institute of Optics and Fine Mechanics in the 1990s. It has been applied in the Shen Guang series of high power laser facilities in China for more than ten years ${ }^{[7]}$. In recent years, different technologies concerning the mass fabrication of large aperture N31 laser glass have been explored ${ }^{[8]}$. In this paper we present the composition, main properties, and fabrication techniques of large aperture N31 glass.

\section{Compositions and properties of N31 phosphate laser glass}

Similar to other neodymium phosphate laser glasses used in an ICF facility, N31 glass is a kind of metaphosphate glass composed of $\mathrm{P}_{2} \mathrm{O}_{5}-\mathrm{R}_{2} \mathrm{O}-\mathrm{MO}-\mathrm{T}_{2} \mathrm{O}_{3}$. $\mathrm{R}_{2} \mathrm{O}$ represents an alkali oxide. $\mathrm{MO}$ represents an alkaline oxide. $\mathrm{T}_{2} \mathrm{O}_{3}$ represents mixtures of $\mathrm{Al}_{2} \mathrm{O}_{3}, \mathrm{La}_{2} \mathrm{O}_{3}$, and $\mathrm{Nd}_{2} \mathrm{O}_{3}$. Up to $5 \mathrm{wt} \% \mathrm{Nd}_{2} \mathrm{O}_{3}$ can be easily doped in $\mathrm{N} 31$ glass without obvious change of properties besides density and refractive 
Table 1. Main parameters of neodymium phosphate laser glasses from Hoya ${ }^{[1]}$, Schott ${ }^{[1]}$, Russia (GOI) ${ }^{[4,9]}$, and SIOM.

\begin{tabular}{llll}
\hline Parameters & $\mathrm{N} 31$ & LHG- & LG-770 \\
\hline$\sigma / 10^{-20} \mathrm{~cm}^{2}$ & 3.8 & 3.6 & 3.9 \\
$* \tau_{\text {rad }} / \mu \mathrm{s}$ & 351 & 365 & 351 \\
$\Delta \lambda_{\text {eff }} / \mathrm{nm}$ & 25.8 & 26.5 & 25.4 \\
$* \mathrm{~d} / \mathrm{g} / \mathrm{cm}^{3}$ & 2.87 & 2.83 & 2.59 \\
$* n_{\mathrm{d}}$ & 1.540 & 1.5296 & 1.5067 \\
$n_{1053 \mathrm{~nm}}$ & 1.533 & 1.5201 & 1.4991 \\
$\mathrm{Abbe}$ number & 65.8 & 66.5 & 68.4 \\
$n_{2} / 10^{-13}$ esu & 1.18 & 1.12 & 1.01 \\
$\mathrm{Tg} /{ }^{\circ} \mathrm{C}$ & 450 & 485 & 460 \\
$\alpha / 10^{-7} / \mathrm{K}\left(20-100^{\circ} \mathrm{C}\right)$ & 115 & 115 & 116 \\
$\mathrm{dn} / \mathrm{dT} / 10^{-7} / \mathrm{K}$ & -43 & -53 & -47 \\
$\mathrm{dS} / \mathrm{dT} / 10^{-7} / \mathrm{K}$ & 14 & 6 & 11 \\
$\mathrm{k} / \mathrm{W} / \mathrm{m} \mathrm{K}$ & 0.56 & 0.58 & 0.57 \\
$\mathrm{E} / \mathrm{Gpa}$ & 56.4 & 50.1 & 47.3 \\
\hline
\end{tabular}

* Parameters which vary with $\mathrm{Nd}_{2} \mathrm{O}_{3}$ concentration.

index. Its composition is satisfied for the requirements of mass fabrication and laser facility applications.

A comparison of the main basic properties of N31 with those of LHG-8, LG-770, and KGSS-0180 glasses is given in table 1 . The most important property of neodymium laser glass is gain coefficient. It is expressed in eq. (1). In order to get optimal gain properties and energy extraction efficiency from neodymium phosphate laser glass, the stimulated emission cross section at emission peak wavelength is required to be in the range 3.5 to $4.0 \times 10^{-20} \mathrm{~cm}^{2}$ for ICF applications.

$$
\mathrm{g}=\left[\sigma(\lambda) N^{*}-\alpha\right],
$$

where $\sigma$ is the emission cross section at wavelength $\lambda$. For $\mathrm{Nd}$ :phosphate glass, the maximum emission cross section in the near infrared region is at $1053 \mathrm{~nm}$. $\mathrm{N}^{*}$ is the $\mathrm{Nd}^{3+}$ inversion density in the ${ }^{4} \mathrm{~F}_{3 / 2}$ state. It is determined by the fluorescent lifetime and fluorescence effective bandwidth of this state. $\alpha$ is the attenuation at laser wavelength. In order to obtain a high gain coefficient, large stimulated emission cross section and long fluorescent lifetime are preferred.

The stimulated emission cross section of N31 glass is higher than that of LHG-8 glass and close to that of LG-770 glass. In order to suppress the damage from self focus due to the optical nonlinear effect at high peak energy fluence, the nonlinear refractive index $\mathrm{n}_{2}$ of neodymium phosphate laser glass should be controlled. From Table 1 it is seen that $\mathrm{n}_{2}$ is below $1.2 \times 10^{-13}$ esu for these $\mathrm{Nd}$ :phosphate glasses.

The laser gain curves of N3122 and N3130 glasses, with $2.2 \mathrm{wt} \%$ and $3.0 \mathrm{wt} \% \quad \mathrm{Nd}_{2} \mathrm{O}_{3}$ doping concentration, were detected at various xenon lamp pumping voltages. The fluorescence lifetime and optical loss at $1053 \mathrm{~nm}$ will have an important influence on the small signal gain. Only samples with an optical loss of $0.1-0.15 \% \mathrm{~cm}^{-1}$ and a lifetime of $340 \mu \mathrm{s}$ (for $2.2 \mathrm{wt} \%$ ) or $320 \mu \mathrm{s}$ (for $3.0 \mathrm{wt} \%$ ) were chosen for measurement. The results, shown in Figure 1, were detected by the same experimental setup and under the same pumping conditions. It clearly indicates that the small signal gain of $\mathrm{N} 31$ neodymium phosphate laser glass increases with $\mathrm{Nd}_{2} \mathrm{O}_{3}$ concentration.

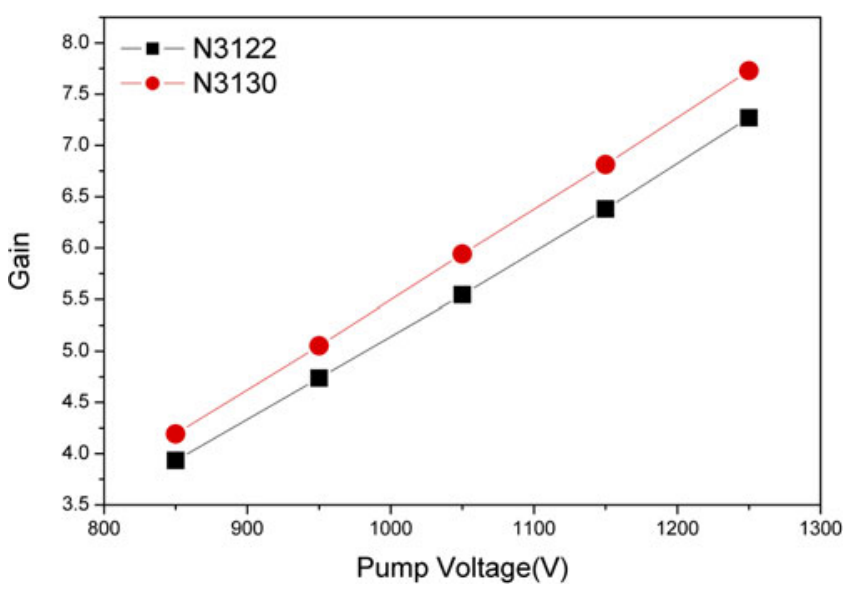

Figure 1. Gain profiles of $\mathrm{N} 3122$ and $\mathrm{N} 3130$ glass rods of size $\Phi$ $8 \times 162 \mathrm{~mm}$ at various xenon lamp pumping voltages. N3122 and N3130 correspond to the glasses with $\mathrm{Nd}_{2} \mathrm{O}_{3}$ concentration of $2.2 \mathrm{wt} \%$ and 3.0 wt $\%$.

\section{Melting technologies of $400 \mathrm{~mm}$ large aperture N31 phosphate laser glass}

It is well known that most of the key parameters of laser glass such as fluorescent lifetime, number of platinum inclusions, bubble and optical homogeneity, birefringence, optical attenuation at lasing wavelength, residual $\mathrm{OH}^{-}$, and absorption at $400 \mathrm{~nm}$ are determined by the fabrication technology. The fabrication process of a laser glass slab includes melting, forming, rough annealing, fine annealing, and edge cladding. The fabrication technology, especially the melting technology, is very important in ensuring the quality of laser glass. An N31 glass rod with diameter $90 \mathrm{~mm}$ and a slab with a clear aperture of $400 \mathrm{~mm}$ have been fabricated in SIOM.

The melting technology of N31 glass has been explored since the mid 1990s, and several fabrication technologies concerning pot melting of N31 laser glass were developed 
in early 2000. A patented pot melting technology has been established instead of traditional two-step melting ${ }^{[10]}$. The glass melt was directly flowed into a platinum crucible to refine and homogenize after the primary melting and dehydration in a refractory crucible. This patented pot melting method ensures a lower degree of contamination by impurities and high efficiency of dehydration.

High purity raw materials with $\mathrm{Fe}, \mathrm{Cu}, \mathrm{Cr}, \mathrm{Ni}$, and $\mathrm{V}$ trace elements (less than $3 \mathrm{ppm}$ ) have been domestically fabricated. Through the controlling of the purity of raw materials and melting processing, the total amount of transition metal oxides is less than 10 ppm in N31 glass. Research has been done on the effect of $\mathrm{Fe}$ and $\mathrm{Cu}$ impurities on the optical attenuation of $\mathrm{N} 31$ glass $^{[11,12]}$. It is found that the most harmful trace element is copper ions, which can seriously affect the optical absorption at laser wavelength even at an amount of only several tens of ppb in glass ${ }^{[12]}$. The high purity raw materials and patented pot melting technology make the attenuation at lasing wavelength lower than $0.15 \% \mathrm{~cm}^{-1}$. Using the reactive atmosphere processing (RAP) dehydration method ${ }^{[6,13]}$, the absorption at $3000 \mathrm{~cm}^{-1}$ can be controlled to be less than $1 \mathrm{~cm}^{-1}$ in N31 glass produced by pot melting. Platinum inclusions were removed by controlling the redox condition of glass melting in order to ionize the metallic platinum ${ }^{[14]}$.

The pot melting efficiency is too low to manufacture thousands of laser glass slabs. Since 2006, research on continuous melting technology of N31 glass has been carried out. The continuous melting technology of large aperture laser glass is more complicated than that of traditional optical glass due to its special technical parameters. Based on the matured laser glass fabrication technology of pot melting ${ }^{[10]}$ as well as theoretical and small scale experimental modeling ${ }^{[15,16]}$, we successfully developed a continuous melting technology for N31 laser glass ${ }^{[17]}$.

The continuous melting line of N31 laser glass consists of an interconnected melter, conditioner, refiner, homogenizer, forming, and annealing lehr. Figure 2 shows the N31 glass running from the annealing lehr in a continuous melting line. Large size N31 glass with thickness greater than $50 \mathrm{~mm}$ and width of about $500 \mathrm{~mm}$ was formed through a platinum pipe into a special mold. A series of technical issues has been overcome in which the greatest challenges are melting batched raw materials with low contamination from refractory materials, dehydration, forming, and fracture in the annealing lehr. Now $400 \mathrm{~mm}$ large aperture N31 laser glass can be fabricated by both pot melting and continuous melting in SIOM.

Table 2 lists the main parameters of mass produced N31 glass with $3.5 \mathrm{wt} \% \mathrm{Nd}_{2} \mathrm{O}_{3}$ (denoted $\mathrm{N} 3135$ ). The absorption coefficients at $3333 \mathrm{~nm}\left(3000 \mathrm{~cm}^{-1}\right)$ and $400 \mathrm{~nm}$ were measured with a commercial Nicolet 6700 FTIR Infrared Spectrometer and Lambda UV/VIS/NIR 1050Spectrophotometers with a glass sample of size $10 \times 10 \times 20 \mathrm{~mm}^{3}$.

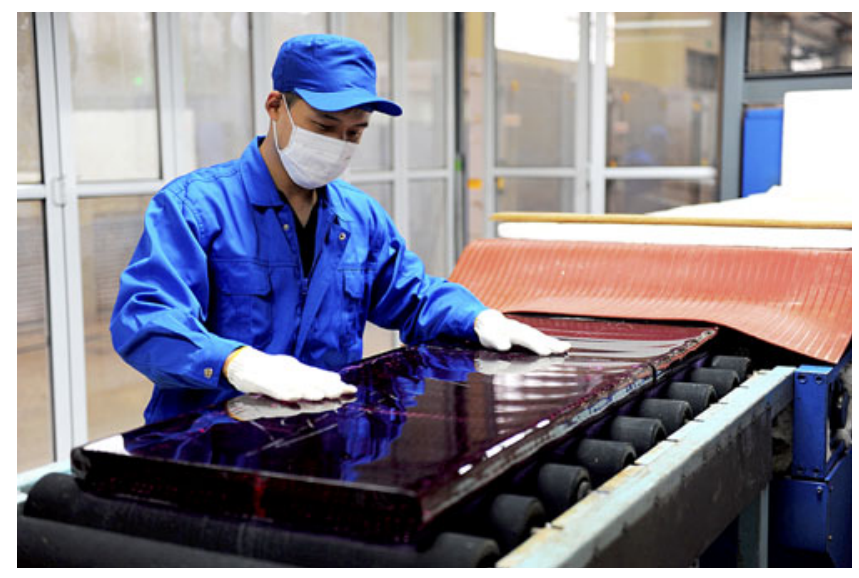

Figure 2. Large size N31 glass running from the annealing lehr of a continuous melting line.

The loss at lasing wavelength was measured with a selfmade double beam spectrometer using a Nd:YAG laser using a glass rod of size $\Phi 8 \times 160 \mathrm{~mm}^{3}$. The fluorescence lifetime was measured with an Edinburgh FLSP920 time resolved fluorescence spectrometer with a glass sample of size $10 \times 10 \times 10 \mathrm{~mm}^{3}$. The refractive index of the glass at a wavelength of $587.6 \mathrm{~nm}$ was measured with a Shimadzu KPR-2000 Refractometer. The optical homogeneity of the glass slab was measured and calculated using a Zygo 24" MST interferometer. A $650 \mathrm{~nm}$ laser diode was used to measure the platinum inclusions of full size $400 \mathrm{~mm}$ aperture N31 glass slab. A TEM 00 Nd:YAG laser with a pulse width of $12 \mathrm{~ns}$ was used to detect the bulk laser damage threshold of N3135 glass.

In the measurement of the single shot laser induced bulk damage threshold (bulk LIDT), ISO 11254-1 was taken as a standard ${ }^{[18]}$. Because the polished surface is the weakest part of the glass sample under laser radiation, the laser beam was focused into the sample by a lens with $100 \mathrm{~mm}$ focal length to evaluate the bulk LIDT. The spot size was measured with a beam analyzer, and the effective spot area was about $0.02 \mathrm{~mm}^{2}$. The test error of the spot size is about $25 \%$ because of the highly convergent beam. The laser energy on the target was controlled by an attenuator, and the pulse energy was recorded for each shot by an energy meter from a split-off portion of the beam. The fluctuation of output energy was 3\%. A He-Ne laser was used to monitor the glass sample, and high sensitivity on-line damage detection was performed by using a microscopy system. Under the condition of $12 \mathrm{~ns}$ pulse width, the damage threshold is around $85.2-86.2 \mathrm{~J} / \mathrm{cm}^{2}$. Accordingly, the calculated threshold for N3135 neodymium phosphate laser glass is around 42.6-43.2 J/ $/ \mathrm{cm}^{2}$ under a $3 \mathrm{~ns}$ laser radiation.

Figure 3 shows a comparison of the gain coefficient of N3135 glasses produced by pot melting and continuous melting. A $4 \times 2 \times 3$ amplifier module, where the $n \times m \times q$ designation denotes the slab number 
Table 2. Parameters of mass production N3135 glass.

\begin{tabular}{lc}
\hline Parameters & Data \\
\hline Attenuation at $1053 \mathrm{~nm}\left(\mathrm{~cm}^{-1}\right)$ & $0.10-0.14 \%$ \\
Fluorescent lifetime $(\mu \mathrm{s})$ & $310-315$ \\
$\mathrm{n}_{d}$ & $1.540 \pm 0.001$ \\
Absorption coefficient at $400{\mathrm{~nm}\left(\mathrm{~cm}^{-1}\right)}^{-1}\left(\mathrm{~cm}^{-1}\right)$ & $0.12-0.23$ \\
Absorption coefficient at $3000 \mathrm{~cm}^{-12}$ & $0.5-1.8$ \\
Optical homogeneity & $\sim 2 \times 10^{-6}$ \\
Platinum inclusion & No platinum for more than $80 \%$ glass slabs \\
Damage threshold at $1064 \mathrm{~nm}, 3 \mathrm{~ns}$ & No bulk damage at $42 \mathrm{~J} / \mathrm{cm}^{2} \mathrm{energy} \mathrm{influence}$ \\
\hline
\end{tabular}

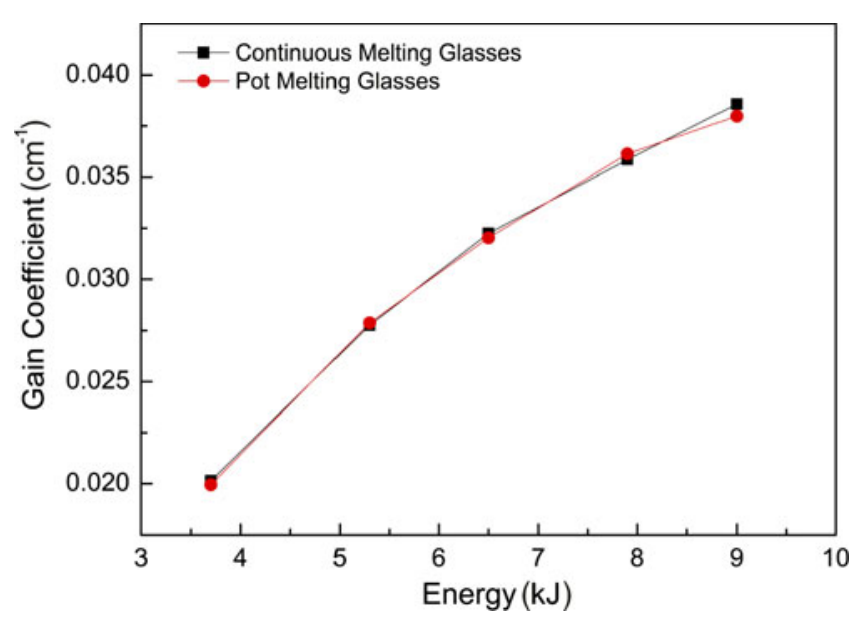

Figure 3. Gain coefficient of $400 \mathrm{~mm}$ aperture N3135 glass slabs from pot melting and continuous melting.

(height $\times$ width $\times$ length) of parallel amplifying channels, was used to measure the small signal gain coefficient. The tested rectangular glass slabs of $810 \times 460 \times 40 \mathrm{~mm}^{3}$ were placed in the amplifier module and oriented at the Brewster angle with respect to the input beam with aperture of $380 \times 380 \mathrm{~mm}^{2}$, respectively. The central flashlamps cassettes with eight flashlamps pump glass slabs in both directions, while two sided flashlamp cassettes, each with six flashlamps and large silver reflectors, pump glass slabs in one direction. These flashlamps are configured as 20 circuits, with each circuit having two flashlamps in series. The operating voltage is from 15 to $23.5 \mathrm{kV}$, the capacitance is $308 \mu \mathrm{F}$ per circuit, and the duration of discharge is $360 \mu \mathrm{s}$. When the charge voltage is $23.5 \mathrm{kV}$, the power condition module will deliver nominally $92 \mathrm{~kJ}$ of energy to each flashlamp pair during the main discharge pulse. In Figure 3, it can been seen that the N3135 laser glasses produced by the pot melting and continuous melting techniques provide nearly the same gain performance.

A typical $633 \mathrm{~nm}$ transmitted wavefront of $400 \mathrm{~mm}$ aperture N3135 laser glass, which was measured by Zygo interferometer with a test aperture of $600 \mathrm{~mm}$, is shown in Figure 4. To measure the optical homogeneity of one $810 \times 460 \times 43.7 \mathrm{~mm}^{3}$ glass slab with a wedge angle of $1^{\prime}-5^{\prime}$, a four-step procedure ${ }^{[19]}$ was done on the digital phase-shift Fizeau interferometer, for both the left and the right part of the slab. Figure 4 shows the $633 \mathrm{~nm}$ transmitted wavefront of the left and the right parts of the same glass slab. The peak and valley (PV) data shown in Figure 4 are the results obtained by subtracting the PV of two reflection surfaces of the slab, as well as PV of the empty cavity of the interferometer, by the same $400 \mathrm{~mm}$ aperture testing laser beam normal to the slab surface. In the light of the PV values shown in Figures $4 \mathrm{a}$ and $4 \mathrm{~b}$, the optical homogeneity $\Delta \mathrm{n}$ of the slab can be estimated by $\Delta n=\mathrm{PV} * 632.8 \mathrm{~nm} / t$, where $t$ is the thickness of the slab. Thus, the optical homogeneity of the refractive index is $2.6 \times 10^{-6}$ and $2.5 . \times 10^{-6}$, for the left and right $400 \times 400 \mathrm{~mm}^{2}$ aperture of the N3135 slab, respectively. The testing precision of optical homogeneity by this four-step procedure method is about $1 \times 10^{-6}$.

\section{Edge cladding of N31 phosphate laser glass}

Edge cladding is an important technology to suppress the amplified stimulated emission ASE and to ensure the gain properties of large size $\mathrm{Nd}$ :phosphate glass. $\mathrm{Cu}^{2+}$ ion doped phosphate glass with a precise refractive index match to N31 laser glass has been designed as a cladding glass. A kind of self-developed epoxy adhesive agent with precise refractive index match to both the laser glass and the cladding glass is used to bond these two glasses. It provides an adhesive strength of $18 \mathrm{MPa}$. This adhesive agent has been tested to be highly resistant to high intensity pump and laser power as well as humid environments in the polishing process.

The $\mathrm{Cu}^{2+}$ doping level is limited by the temperature rise at the interface between the cladding glass and the laser glass. This temperature rise is due to strong absorption of ASE energy of a laser pulse. The temperature rise $\Delta T$ after a laser shot can be expressed by

$$
\Delta T(x)=\frac{\beta I_{O}}{\rho \cdot C_{P}} \exp (-\beta x),
$$

where $x$ is the distance from the interface to the inside of laser glass. $I_{0}$ is the pumping energy fluence. $\rho$ is the density of the cladding glass. $\mathrm{C}_{p}$ is heat capacity. $\beta$ is absorption coefficient of cladding glass at $1 \mu \mathrm{m}$. The absorption 


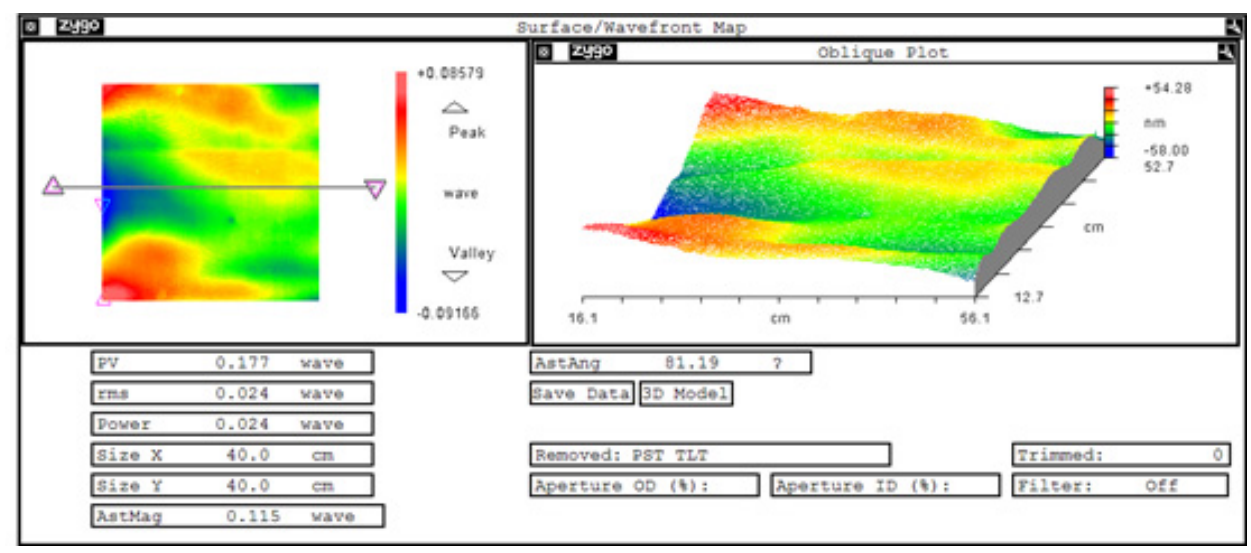

(a) the left part of $400 \times 400 \mathrm{~mm}^{2}$

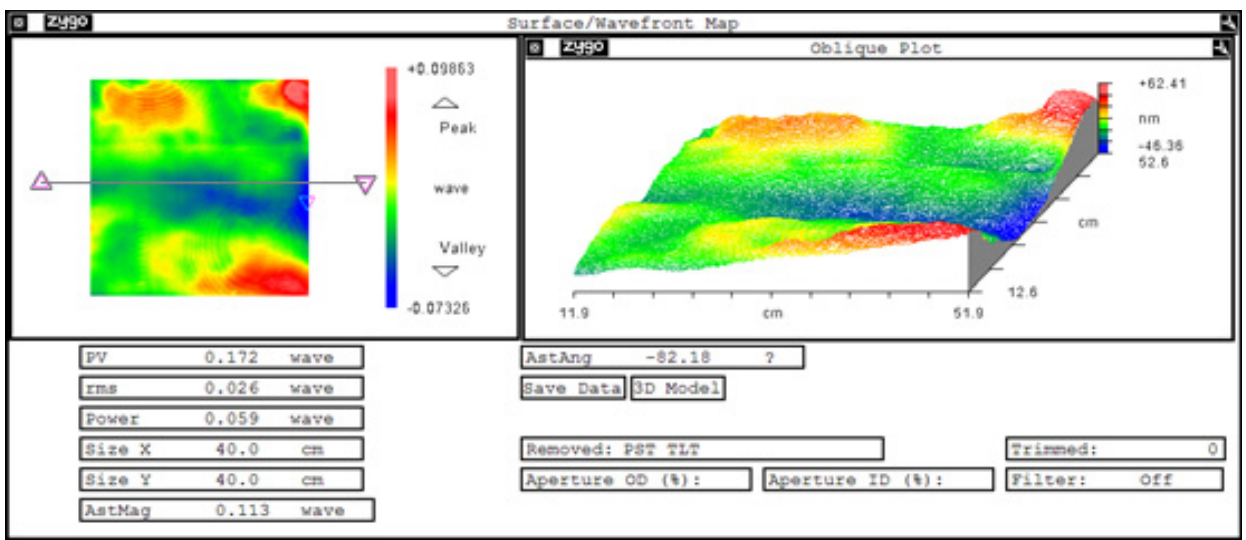

(b) the right part of $400 \times 400 \mathrm{~mm}^{2}$

Figure 4. $633 \mathrm{~nm}$ transmitted wavefront of a N3135 glass slab of size $810 \times 460 \times 43.7 \mathrm{~mm}^{3}$. (a) The left part of $400 \times 400 \mathrm{~mm}^{2}$ and (b) the right part of $400 \times 400 \mathrm{~mm}^{2}$.

coefficient of $\mathrm{Cu}^{2+}$ doped cladding glass is usually $3-5 \mathrm{~cm}^{-1}$ at $1053 \mathrm{~nm}$ to suppress the temperature rise between the interface of the cladding and laser glasses. A small temperature rise can limit the thermal stress around the interface between the cladding glass and the laser glass after a laser shot.

A patented edge cladding technique has been developed for large aperture N31 laser glass ${ }^{[20]}$. It has been applied in the fabrication of large aperture N31 laser glass slab. More than 10,000 shots of high energy fluence have been applied in our edge cladding N31 glass slab in the Shen Guang facility.

The residual stress caused by edge cladding is kept small by the proper choice of adhesive agent and its curing parameters. Figure 5 shows the averaged stress distribution within $50 \mathrm{~mm}$ distance to the interface of the cladding for a $400 \mathrm{~mm}$ aperture N31 laser glass slab before and after cladding, which was scanned with a Strain Optics DIAS 1600 stress analyzer. The test area is $70 \times 100 \mathrm{~mm}^{2}$ for one time scanning. In the measurement, the polarized beam is normal to the surface of the slab. The averaged result indicates that this patented cladding technique does not induce additional stress

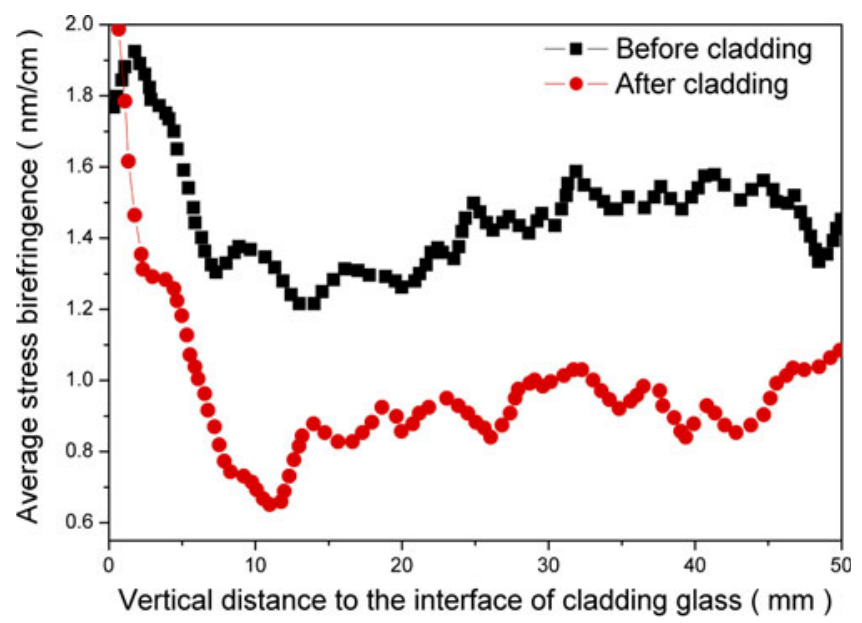

Figure 5. The stress distribution of $400 \mathrm{~mm}$ aperture N31 glass slab before and after cladding.

inside the neodymium glass $12 \mathrm{~mm}$ away from the interface between the neodymium glass and the cladding glass. 


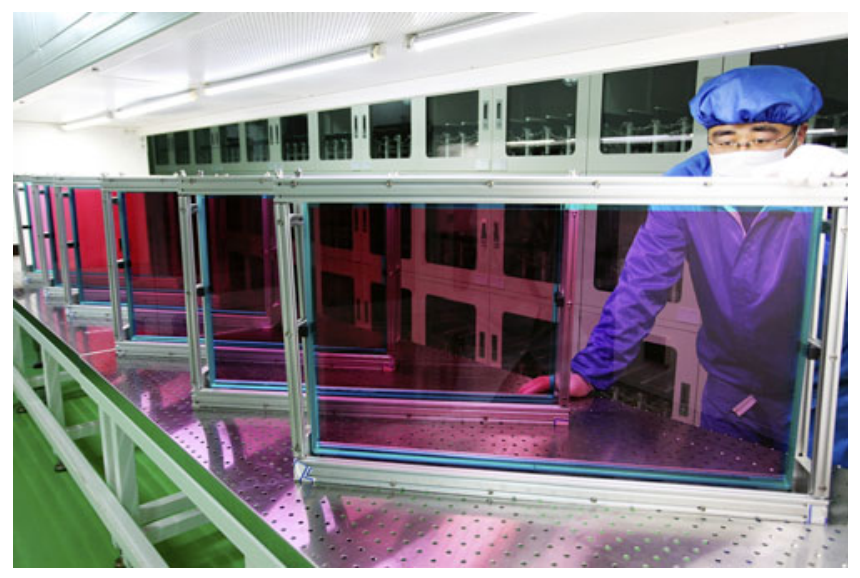

Figure 6. $400 \mathrm{~mm}$ aperture N31 glass slabs before installation.

Figure 6 shows $400 \mathrm{~mm}$ aperture N31 laser glass slabs with edge cladding after fine polishing and cleaning. These glass slabs have been successfully applied in the Shen Guang facility.

\section{Conclusions}

The main composition and properties of N31 Nd-doped phosphate laser glass are reported. Three key techniques for laser glass fabrication (pot melting, continuous melting, and edge cladding) have been developed in Shanghai Institute of Optics and Fine Mechanics. The glass parameters and laser gain of $\mathrm{N} 3135$ phosphate glass produced by continuous melting are almost the same as those obtained by pot melting. $400 \mathrm{~mm}$ clear aperture N31 glass slabs with high quality have been fabricated for building the Shen Guang high peak power laser facilities in China.

\section{References}

1. J. H. Campbell, and T. I. Suratwala, J. Non-Cryst. Solids 263\&264, 318 (2000).
2. E. Hand, Nature, doi:10.1038/nature.2012.10269.

3. J. H. Campbell, T. I. Suratwalaa, C. B. Thorsnessa, J. S. Haydenb, A. J. Thorneb, J. M. Ciminob, A. J. Marker IIIb, K. Takeuchic, M. Smolleyc, and G. F. Ficini-Dornd, J. Non-Cryst. Solids 263\&264, 342 (2000).

4. V. I. Arbuzov, Y. K. Fyodorov, S. I. Kramarev, S. G. Lunter, S. I. Nikitina, A. N. Pozharskii, A. V. Shashkin, A. D. Semyonov, V. E. Ter-Nersesyants, A. V. Charukhchev, V. S. Sirazetdinov, S. G. Garanin, and S. A. Sukharev, Glass Technol. 46, 67 (2005).

5. Z. Jiang, Chin. J. Lasers 33, 1265 (2006) (in Chinese).

6. Y. Jiang, J. Zhang, W. Xu, Z. Ma, X. Ying, H. Mao, S. Mao, and J. Li, J. Non-Cryst. Solids 80, 623 (1986).

7. L. Hu, and Z. Jiang, Bull. Chin. Ceramics Society 25, 125 (2005) (in Chinese).

8. L. Hu, S. Chen, T. Meng, W. Chen, J. Tang, B. Wang, J. Hu, L. Wen, S. Li, Y. Jiang, J. Zhang, and Z. Jiang, High power laser and particle beams 23, 2560 (2011) (in Chinese).

9. V. I. Arbuzov, Yu. K. Fedorov, S. I. Kramarev, and A. V. Shashkin, J. Opt. Technol. 80, 321 (2013).

10. J. Zhang, H. Mao, S. Chen, X. Ying, B. Wang, B. Zhou, H. Zhu, and C. Jin, Chinese patent ZL 00127617.4.

11. Y. Xu, S. Li, L. Hu, and W. Chen, Chin. Opt. Lett. 3, 701 (2005)

12. Y. Xu, S. Li, L. Hu, and W. Chen, J. Rare Earths 29, 614 (2011).

13. D. Zhuo, W. Xu, and Y. Jiang, Chin. J. Laser 12, 173 (1985).

14. B. Zhou, L. Hu, Y. Jiang, H. Mao, and J. Zhang, Chin. J. Lasers 28A, 837 (2001).

15. J. Tang, L. Hu, and F. Gan, J. Wuhan Univ. Technol. 29, Suppl.1, 210 (2007).

16. J. Tang, L. Hu, X. Ying, C. Jin, and F. Gan, Glass \& Enamel (Monograph) 30 (2007).

17. J. Tang, B. Wang, and L. Hu, Annual Reports on Inertial Confinement Fusion of China Academy of Engineering Physics (2011) 1.

18. ISO11254-1. 2000. Lasers and laser-related equipment Determination of laser-induced damage threshold of optical surfaces - Part 1: 1-on-1 test.

19. J. Schwider, R. Burow, K.-E. Elssner, and R. Spolaczyk, J. Grzanna, Appl. Opt. 24, 3059 (1985).

20. T. Meng, J. Tang, J. Hu, L. Wen, L. Chen, W. Chen, and L. Hu, Chinese Patent, ZL 201010273819.7. 